Tropical Journal of Pharmaceutical Research May 2017; 16 (5): 1105-1112

ISSN: $1596-5996$ (print); 1596-9827 (electronic)

(C) Pharmacotherapy Group, Faculty of Pharmacy, University of Benin, Benin City, 300001 Nigeria.

All rights reserved.

Available online at http://www.tjpr.org

Original Research Article

http://dx.doi.org/10.4314/tjpr.v16i5.19

\title{
Evaluation of adsorption capacity of acetaminophen on activated charcoal dosage forms available in Nigeria by in vitro adsorption studies and scanning electron microscopy
}

\author{
Margaret $O$ llomuanya ${ }^{1,2 \star}$, Angela F Ohere ${ }^{1}$, Sa'adat A Zubair ${ }^{1}$ and Uloma \\ Ubani-Ukoma ${ }^{1}$ \\ ${ }^{1}$ Department of Pharmaceutics and Pharmaceutical Technology, Faculty of Pharmacy, University of Lagos, PMB 12003, \\ Surulere, Lagos, Nigeria, ${ }^{2}$ School of Pharmacy, Faculty of Science, University of Nottingham Malaysia Campus, Jalan Broga, \\ 4300 Semenyih, Malaysia
}

*For correspondence: Email: milomuanya@live.com; milomuanya@unilag.edu.ng

\begin{abstract}
Purpose: To investigate varying dosage forms of activated charcoal obtained from community pharmacy outlets in Nigeria for their adsorption capacity when challenged with acetaminophen.

Methods: Equilibruim kinetics of acetaminophen adsorption onto activated charcoal surface was determined via batch studies at different adsorbent:adsorbate ratios. The isotherm adsorption experiment was carried out at $37{ }^{\circ} \mathrm{C}$ and langmuir isotherm models were utilized to describe the equilibrium kinetics data with characterization of adsorption site and porosity elucidated via scanning electron microscopy.

Results: A preponderance of microporosity was observed on the surface of the powder activated charcoal. Maximum adsorption capacity (MAC) of $299.78 \mathrm{mg} / \mathrm{g}$ was obtained using activated charcoal powder (276.11; 321.09) at $95 \%$ confidence interval $(\mathrm{Cl})$, allowing for maximum adsorption of acetaminophen at $\mathrm{pH}$ 1.2. Mixed pore structures, which were not clearly established, were observed with both the tablets and capsules with MAC of $280.54 \mathrm{mg} / \mathrm{g}$ (273.22; 290.08) and $140.01 \mathrm{mg} / \mathrm{g}$ (135.32; 153.99), respectively at $\mathrm{pH}$ 1.2. MAC data at $\mathrm{pH} 6.5$ showed little variation from those obtained at $\mathrm{pH}$ $1.2(p<0.0595 \% \mathrm{Cl})$.

Conclusion: The presence of excipients in the tablets and capsules caused a retardation in adsorption via intraparticle diffusion especially at basal micropore sites on the activated charcoal surface. Activated charcoal powder is superior to other dosage forms for use in countering acetaminophen poisoning.
\end{abstract}

Keywords: Acetaminophen, Adsorption, Isotherms, Activated charcoal, Scanning electron microcopy

Tropical Journal of Pharmaceutical Research is indexed by Science Citation Index (SciSearch), Scopus, International Pharmaceutical Abstract, Chemical Abstracts, Embase, Index Copernicus, EBSCO, African Index Medicus, JournalSeek, Journal Citation Reports/Science Edition, Directory of Open Access Journals (DOAJ), African Journal Online, Bioline International, Open-J-Gate and Pharmacy Abstracts

\section{INTRODUCTION}

Acetaminophen overdose is usually managed utilizing activated charcoal. The ease of administration and its relative safety when compared with other gastrointestinal decontamination methods makes it desirable for drug overdose management [1,2]. Large reductions in drug absorption occur when activated charcoal is administered soon after drug ingestion [2]. Some workers evaluated the adsorption of fluoroquinolones on some pharmaceutical adsorbents; it was observed that activated charcoal had a superior adsorption capacity to bentonite and kaolin [3-5].

Acetaminophen an analgesic agent is a leading cause of acute liver failure in the industrialized 
Table 1: Activated charcoal dosage forms utilized

\begin{tabular}{lcccccccc}
\hline $\begin{array}{l}\text { Dosage } \\
\text { forms }\end{array}$ & Excipient & Batch no & $\begin{array}{c}\text { Manuf. } \\
\text { date }\end{array}$ & $\begin{array}{c}\text { Expiry } \\
\text { date }\end{array}$ & $\begin{array}{c}\text { Country } \\
\text { of origin }\end{array}$ & $\begin{array}{c}\text { NAFDAC } \\
\text { Reg. no. }\end{array}$ & $\begin{array}{c}\text { Activated } \\
\text { charcoal } \\
\text { content }(\%)\end{array}$ & $\begin{array}{c}\text { BET } \\
\text { surface } \\
\text { area }\left(\mathbf{m}^{2} / \mathbf{g}\right)\end{array}$ \\
\hline Tablet & Bentonite \& corn starch & 2506701 & $07 / 2012$ & $06 / 2016$ & Germany & $\begin{array}{c}\text { Mal } \\
19910964 x\end{array}$ & 65.3 & 1713 \\
Capsule & $\begin{array}{c}\text { Gelatin \& magne-sium } \\
\text { stearate (vegetable) }\end{array}$ & $12035 \mathrm{c}$ & $08 / 2013$ & $09 / 2016$ & USA & $787-60$ & 35.5 & 1702 \\
Powder & Corn Starch & $11239 \mathrm{~b}$ & $07 / 2013$ & $07 / 2016$ & Nigeria & $04-9941$ & 95.5 & 1942 \\
\hline
\end{tabular}

countries [6,7] .Acetaminophen poisoning has also been reported in Nigeria in pediatric cases as well leading to deaths in more than 40 children [8,9], and in adults who have ingested more than 3 brands of medications for pains which all contain varying concentrations of acetaminophen [10], leading to liver damage except where immediate treatment is given via activated charcoal slurry or the acetyl cysteine antidote [11-13].

The nature of activated charcoal dosage form and its ability to adsorb potential poisons depends on the total pore volume, pore size distribution, prevalence of a certain pore size regime and the behavior of admolecules in these pore regimes [14-17]. It is imperative that the final dosage form of activated charcoal must have pores which have affinity for the adsorbate without interference from excipients $[17,18]$.

In this study varying dosage forms of activated charcoal obatined from community pharmacy outlets were investigated for their adsorption capacity when challenged with acetaminophen intoxication in an in vitro model at varying $\mathrm{pH}$. Previous studies by Panthee and Lohani evaluated intoxication at $\mathrm{pH} 3.4$ and $\mathrm{pH} 7.2$ [18]. The present study, however, seeks to evaluate adsorption kinetics at $\mathrm{pH}$ which mimicks a fasted state of the gastric and intestinal compartments using simulated gastric fluid (SGF) and simulated intestinal fluid (SIF). SEM studies will be utilized to elucidate the areas of drug absoprtion unto the surface of the varying dosage forms of activated charcoal marketed in Nigeria. Maximum adsorption capacity (MAC) data obtained via the adsoprtion isotherm model which best describes their adsorption behaviour will then aid in providing information on the effectiveness of the various dosage forms to be used especially in emergency medical situations.

\section{EXPERIMENTAL}

\section{Materials}

The adsorbate used all through was acetaminophen, pure standard (Sigma Aldrich ${ }^{\circledR}$ USA), Acetaminophen tablets (Innovator product) Panadol $^{\circledR}$ manufactured by GlaxoSmithKline (GSK) Nigeria with NAFDAC registration number 04-0205 was purchased from a registered retail pharmacy outlet in Lagos, Nigeria.

The adsorbents comprised of three dosage forms of activated charcoal, shown in Table 1, sourced via random sampling from community pharmacies in Lagos, Nigeria and were used within their shelf life. The varying characteristics of the dosage forms including the quantities $\% \mathrm{w} / \mathrm{w}$ of activated charcoal were provided by the manufacturer.

Potassium dihydrogen phosphate (Thomas Baker $^{\circledR}$ UK), sodium bicarbonate (Sigma Aldrich ${ }^{\circledR}$ USA), Sodium hydroxide (Thomas Baker ${ }^{\circledR}$ UK), Methanol (Sigma Aldrich ${ }^{\circledR}$ USA), Hydrochloric Acid (Sigma Aldrich ${ }^{\circledR}$ USA) and LC grade water (Omnisolv ${ }^{\circledR}$,) was purchased from EMD Millipore Corp. (Billerica, MA, USA). All solvents and reagents used were of analytical grade and the dissolution media used were always freshly prepared.

\section{Adsorption kinetics studies}

Twenty tablets of acetaminophen were crushed in a clean and dry porcelain mortar and sieved with the aid of a sieve 100 mesh. $900 \mathrm{ml}$ stock solution of acetaminophen $(0.5 \% \mathrm{w} / \mathrm{v})$ in the varying dissolution media was prepared. This was introduced into each dissolution vessel, and the vessel maintained at $37.0 \pm 0.2{ }^{\circ} \mathrm{C}$ operated at $100 \mathrm{rpm}$.

Langmuir isotherm models were utilized to describe the equilibrium kinetics data, via adsorbent: adsorbate ratios being varied from 1:1 through a 10 fold ratio of adsorbent to 1 ratio ofadsorbate. Into the respective dissolution vessels varying quantities of activated charcoal (either as tablets, capsules or as the powder) were introduced in the required adsorbent:adsorbate ratio already predetermined. At specific time intervals, aliquots were 
withdrawn, filtered thrice, and suitably diluted before being analyzed at $244 \mathrm{~nm}$ using a Distek $^{\circledR}$ Dissolution system $21000 \quad$ UV-visible spectrophotometer [20]. Activated charcoal in the different dosage forms were subsequently introduced into the dissolution vessels in the absence of acetaminophen, aliquots were withdrawn from the dissolution medium, filtered thrice, before being analyzed at $244 \mathrm{~nm}$. This did not give any reading and as such it was concluded that the excipients in the dosage forms did not interfere with results obtained.

\section{Adsorption equilibrium studies}

Utilizing the different dosage forms of the activated charcoal, $500 \mathrm{mg}$ of activated charcoal were weighed out and introduced into the bottles containing $500 \mathrm{ml}$ of either SGF or SIF after which the bottles were fastened and sealed. Rotation at $30 \mathrm{rpm}$ was initiated for 30 min using a rotor (Model 103906 motor, LW Scientific ${ }^{\circledR}$ ) at $37{ }^{\circ} \mathrm{C}$ after which the bottles were allowed to settle for 3 hours while still maintained at $37{ }^{\circ} \mathrm{C}$. $5 \mathrm{ml}$ aliquot of the supernatant in each bottle was sampled, after centrifugation at $2000 \mathrm{rpm}$ for 2 min. Studies were repeated at 30 min intervals in twelve replicates after which acetaminophen concentration was determined using the UV spectrophotometer at $244 \mathrm{~nm}$.

\section{Adsorption analysis}

Acetaminophen adsorption was calculated at equilibrium as shown in Eq. 1

$\mathrm{Qe}=\{(\mathrm{Co}-\mathrm{Ce}) \mathrm{V}\} / \mathrm{m}$

where $\mathrm{Qe}$ is the amount of acetaminophen adsorbed per gram of the adsorbent at equilibrium (mg/g); Initial (Co) and final equilibrium $(\mathrm{Ce})$ concentration of acetaminophen in solution in $\mathrm{mg} / \mathrm{L} ; \mathrm{V}(\mathrm{L})$, volume of solution and the amount of adsorbent in grams is $\mathrm{m}$.

MAC of the activated charcoal samples were calculated using Langmuir adsorption isotherm as shown in Eq 2.

$\mathrm{Ce} / \mathrm{Qe}=\mathrm{Ce} / \mathrm{Qm}+1 / \mathrm{KQm}$.

where $Q m(\mathrm{mg} / \mathrm{g})$ is the MAC which is synonymous with a monolayer coverage, $\mathrm{K}$ is the Langmuir proportionality constant/ modal parameter. Data was imputed into Eqs. 1-2 to obtain Langmuir isotherm diagrams and MAC values.

\section{Scanning electron microscopy (SEM)}

Thirty minutes after commencement of the adsorption equilibrium studies $1 \mathrm{ml}$ sample was obtained from the tubes and a minute amount was placed on a stub labeled and viewed using a Quanta 400F SEM FEI USA instrument. This was used to elucidate the areas of drug adsoprtion onto the surface of the varying dosage forms of activated charcoal using a JEOL JSM-6360LA Oxford instrument Software XT microscope control systems. The varying areas of adsorption were observed in both SGF and SIF.

\section{Determination of surface area}

Using the method described by llomuanya et al [20] surface area was determined Brunauer, Emmett and Teller (BET) method. Ten grams of the commercial samples were vortexed in distilled water thrice to remove the excipients on the surface of the charcoal and subsequently dried at $60{ }^{\circ} \mathrm{C}$. Each of three activated carbon samples $(0.2 \mathrm{~g})$ were weighed and degassed under vacuum $(300 \mathrm{mmHg})$ until the pressure was stable at $6 \times 10^{-6}$ torr. and was put in the sample tube and left to constant heating at 250 ${ }^{\circ} \mathrm{C}$ for $10 \mathrm{~h}$, after which surface area analysis was performed.

\section{Statistical analysis}

The data from this study was analyzed using Microsoft Excel sheet and SPSS Inc. version 11.0 Chicago Illinois. A comparison of the standard with mean values was evaluated via ANOVA at $95 \%$ confidence interval $(p<0.05)$.

\section{RESULTS}

\section{Adsorption equilibrium}

Langmuir adsorption isotherms were utilized in describing the adsorption behavior of the adsorbent unto the adsorbate. Langmuir's adsorption is based on 4 major assumptions, that only a monolayer is formed, that the adsorbent and adsorbate species are none interacting, adsorption occurs uniformly across specific homogenous sites inside the pore structure within the adsorbent leading to saturation occurring after which point no other adsorption can occur. Eq 2 is the Langmuir equation where $\mathrm{K}$ is the Langmuir constant which corresponds to the heat energy of adsorption. The maximum adsorption capacity MAC which elucidates the formation of a monolayer coverage (as seen with the initial inflection point in Figure 1 and Figure 2 was calculated from Qm. Figures 1, Figure 2 and 


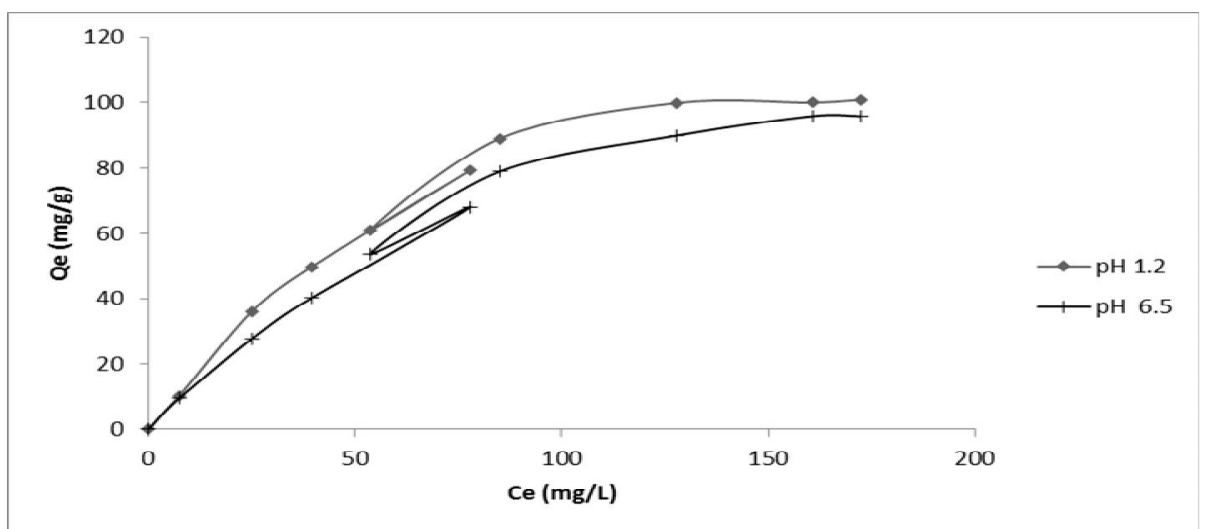

Figure 1: Langmuir adsorption isotherm of acetaminophen using activated charcoal capsule in $\mathrm{pH} 1.2$ and $\mathrm{pH} 6.5$

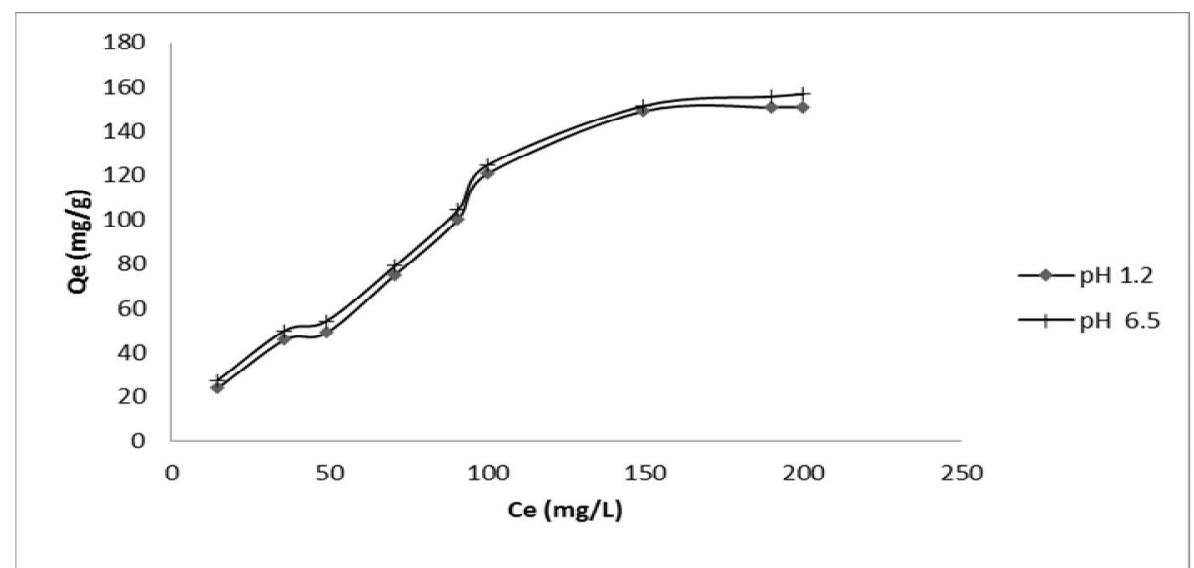

Figure 2: Langmuir adsorption isotherm of acetaminophen using activated charcoal tablet in $\mathrm{pH} 1.2$ and $\mathrm{pH} 6.5$

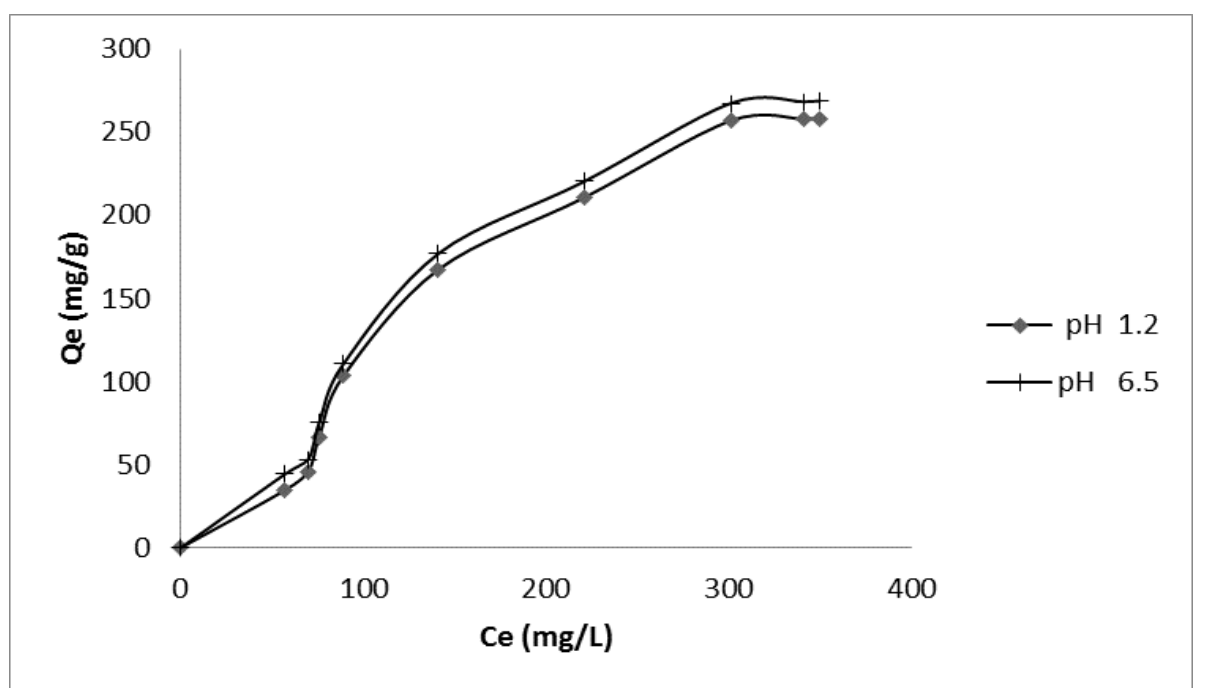

Figure 3: Langmuir adsorption isotherm of acetaminophen using activated charcoal powder in $\mathrm{pH} 1.2$ and pH 6.5

Figure 3 show Langmuir adsorption isotherm of paracetamol by capsules, tablets and powder activated charcoal samples. There was little variation reflected at the two $\mathrm{pH}$ utilized in the study, however $\mathrm{Qe}$ values for $\mathrm{pH} 6.5$ were slightly higher but not statistically significant with $p<0.05$.

\section{Adsorption kinetics}

The solid (activated charcoal) - solution interface where adsorption takes place is controlled by the rate of uptake of acetaminophen as the solute, the time that it is retained on the surface of the adsorbent is also dependent on the acetaminophen uptake rate, and this is described 
by the adsorption kinetics of acetaminophen unto the varying forms of activated charcoal evaluated.

The pseudo first order model was utilized to fit in acetaminophen adsorption unto varying activated charcoal dosage forms as shown in Table 2. Eq 3 represents Qe and Qt $(\mathrm{mg} / \mathrm{g})$ as the amount of acetaminophen adsorbed in one gram of the adsorbent at equilibrium at time $t$ (minutes) with $k_{1}$ being the pseudo first order kinetic rate constant.

Qt $=$ Qe $\left[1-\exp \left(-k_{1} t\right)\right]$

Intraparticle diffusion model was used to analyze the data where $k_{p}\left(\mathrm{mg} / \mathrm{m} / \mathrm{min}^{0.5}\right)$ represents the intra-particle diffusion constant (Eq 4). This model looks at adsorption as beginning first with a rapid adsorption phase followed by a more gradual adsorption process where the intra particle diffusion occurring controls and drives the adsorption process as reflected in Table 2.
$Q t=k_{p} t^{1 / 2}+C$

Maximum adsorption capacity derived from $\mathrm{Eq} 2$, of the three formulations at the $\mathrm{pH} 1.2$ and 6.5 is reflected in Table 2. Significant difference in MAC data between the dosage forms were evident as shown in Table 2 with activated charcoal powder having the highest MAC value at $\mathrm{pH} 6$, this difference wasn't seen in the use of varying media $(p>0.05)$.

Scanning electron microscopic studies revealed that adsorption of acetaminophen occurred on the microporous pores of the powder (Figure 4C and $\mathrm{F}$ ), with increased adsorption densities seen in $3 \mathrm{~F}$ when $\mathrm{pH} 6.5$ was utilized, this is in consonance with MAC values obtained. It was evident that the presence of excipients in the capsule formulation greatly hampered adsorption unto available sites (Figure 4A and D), surface coverage was minimal, the tablet formulation showed more acetaminophen adsorption (Figure 4C and E) than the capsule and this was also buttressed by MAC data in Table 2 .

Table 2: Kinetic model for adsorption of acetaminophen unto varying activated charcoal dosage forms

\begin{tabular}{|c|c|c|c|c|c|c|}
\hline \multirow{2}{*}{\multicolumn{2}{|c|}{$\begin{array}{l}\text { Activated } \\
\text { charcoal dosage } \\
\text { form (Adsorbent) }\end{array}$}} & \multicolumn{2}{|c|}{$\begin{array}{c}\text { Pseudo } 1^{\text {st }} \text { order } \\
\text { model }\end{array}$} & \multicolumn{2}{|c|}{$\begin{array}{c}\text { Intra-particle diffusion } \\
\text { model }\end{array}$} & \multirow{2}{*}{$\begin{array}{c}\text { Maximum adsorption } \\
\text { concentration }(\mathrm{mg} / \mathrm{g})(95 \% \\
\mathrm{Cl})\end{array}$} \\
\hline & & $k_{1}\left(\min ^{-1}\right)$ & $R^{2}$ & $k_{p}$ & $R^{2}$ & \\
\hline \multirow[t]{3}{*}{$\mathrm{pH} 1.2$} & Capsule & 0.0176 & 0.9790 & 0.8432 & 0.9738 & $139.38(135.21 ; 154.25)$ \\
\hline & Tablet & 0.0179 & 0.9971 & 0.8320 & 0.9834 & $276.63(26$ \\
\hline & Powder & 0.0265 & 0.9989 & 0.8432 & 0.9891 & $299.78(276.11 ; 321.09)$ \\
\hline \multirow[t]{3}{*}{ pH 6.5} & Capsule & 0.0099 & 0.9800 & 0.8543 & 0.9771 & $140.01(135.32 ; 153.99)$ \\
\hline & Tablet & 0.0183 & 0.9969 & 0.8519 & 0.9890 & $280.54(273.22 ; 290.08)$ \\
\hline & Powder & 0.0264 & 0.9991 & 0.8509 & 0.9899 & 301.92 (284.33; 320.78) \\
\hline
\end{tabular}

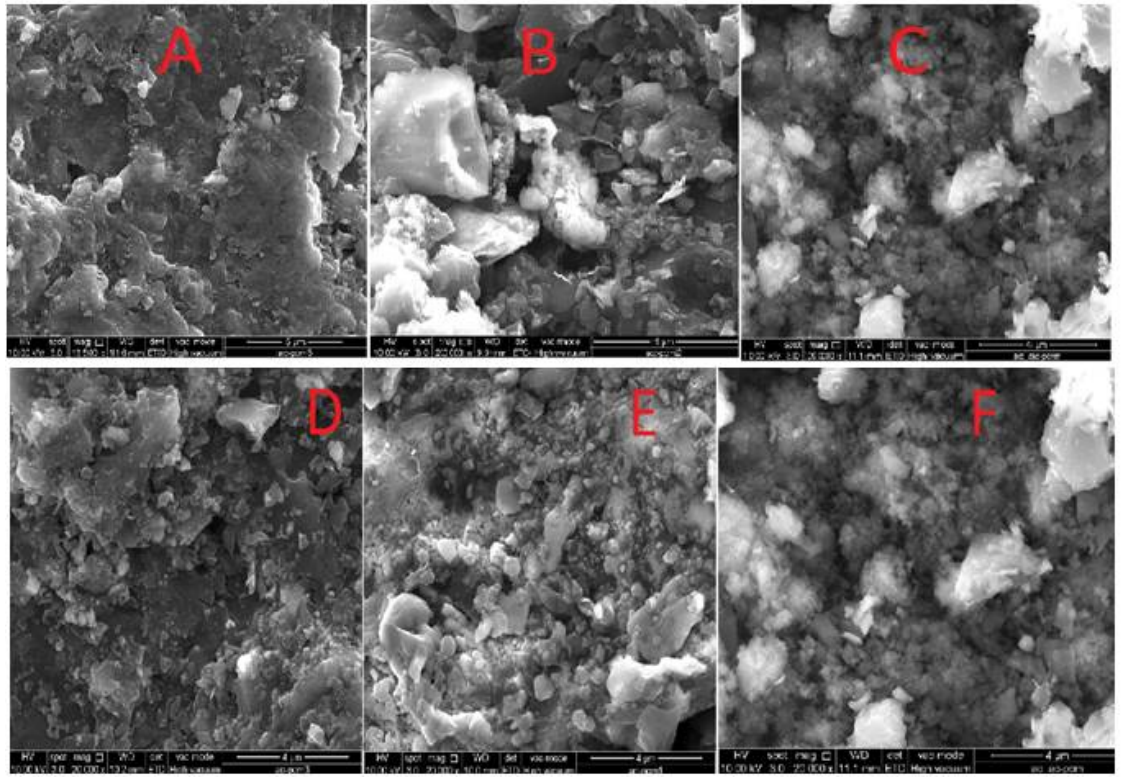

Figure 4: Scanning electron micrograph of particulate surface of activated charcoal obtained from (A) capsule; (B) tablet and (C) powder after adsorption of acetaminophen in SGF and from (D) capsule; (E) tablet and (F) powder after adsorption of acetaminophen in SIF 
Table 3: Experimental values of amount of acetaminophen adsorbed per gram of the adsorbent at equilibrium in different kinetic model

\begin{tabular}{|c|c|c|c|c|c|}
\hline \multirow{2}{*}{\multicolumn{2}{|c|}{$\begin{array}{l}\text { Activated charcoal dosage } \\
\text { form (Adsorbent) }\end{array}$}} & \multicolumn{2}{|c|}{ Pseudo 1st order model } & \multicolumn{2}{|c|}{ Intra-particle diffusion model } \\
\hline & & \multirow{2}{*}{$\begin{array}{c}\boldsymbol{Q} \boldsymbol{e}_{\text {(experimental) }} \\
(\mathbf{m g} / \mathbf{g}) \\
100.90\end{array}$} & \multirow{2}{*}{$\begin{array}{c}\boldsymbol{Q e}_{\text {(predicted) }} \\
\text { (mg/g) }\end{array}$} & \multirow{2}{*}{$\begin{array}{c}\boldsymbol{Q e}_{(\text {experimental) }}(\mathbf{m g} / \mathbf{g}) \\
99.32\end{array}$} & \multirow{2}{*}{$\begin{array}{c}\begin{array}{c}Q \boldsymbol{e}_{(\text {predicted) }} \\
(\mathbf{m g} / \mathbf{g})\end{array} \\
101.22\end{array}$} \\
\hline pH 1.2 & Capsule & & & & \\
\hline & Tablet & 160.32 & 158.32 & 162.33 & 159.77 \\
\hline & Powder & 261.32 & 262.01 & 261.32 & 265.32 \\
\hline \multirow[t]{3}{*}{ pH 6.5} & Capsule & 97.35 & 96.32 & 97.35 & 99.32 \\
\hline & Tablet & 151.02 & 155.32 & 151.02 & 153.32 \\
\hline & Powder & 258.11 & 262.32 & 258.11 & 258.23 \\
\hline
\end{tabular}

\section{DISCUSSION}

Langmuir's assumption that adsorption will occur uniformly as a monolayer unto the adsorbent surface was refuted in this study as adsorption was shown to be varied across the pore surface of the varying activated charcoal dosage forms. A correlation between the quantities of acetaminophen adsorbed and the scanning electron micrographs was observed. There was an increased density of acetaminophen adsorption on the activated charcoal (AC) microporous surface. The powdered activated charcoal was most suited for adsorption of acetaminophen. This result is similar to that obtained by other workers [18] where both the powdered activated charcoal and the activated charcoal slurry both had MAC that were much higher than those obtained from other activated charcoal dosage forms which he evaluated.

A preponderance of microporosity was observed with the powder activated charcoal adsorption occuring on the micropore surface, the adsorption was a good fit to the langmuir isotherm, which allowed for maximum adsorption capacity (MAC) of acetaminophen at $\mathrm{pH}$ 1.2. A preponderance of mixed pore structures which were not clearly established was observed with both the tablets and capsules. Consequently BET surface surface area was much lower for the tablets and capsules, when compared to the powder dosage form. Scanning electron micrographs showed that adsorption did not take place on the surface of the activated charcoal because these adsorption sites were unavailable for acetaminophen adsorption.

Very high correlation was obtained using the pseudo first order kinetic model when compared with intra-particle diffusion model with $R^{2}$ values of 0.991 in $\mathrm{pH} 6.5$ for the acetaminophen adsorption via powdered activated charcoal, thus reflecting high correlation coefficients. This model suggests that physisorption is the rate controlling mechanism via which adsorption takes place and this is buttressed by the close values obtained for predicted and experimental Qe for drug adsorption.

Adsorption may also have been influenced by the functional groups associated with the surface of the activated charcoal. Excipient interactions with the functional group on the surface of the AC leads to variation in MAC values and this accounts principally for the lower values obtained from capsule activated charcoal, as this was formulated with the most excipient \%w/w concentration. This associated interaction lends credence to the reduced acetaminophen adsorption density observed in the SEM. Excipients utilized in the formulation of the activated charcoal capsule and tablets act as deterrents to acetaminophen adsorption as they may contribute either acidic or basic functional groups to the surface of the activated charcoal leading to an interaction between the adsorbent and adsorbate functional groups thus making the micro and macro pore surfaces unavailable for adsorption. $R^{2}$ values obtained via the intraparticle diffusion model were close to 1 , which is suggests that adsorption was initially very fast but was followed by a gradual adsorption stage indicative of adsorption occurring through the intra-particle space via diffusion [19], and this process drives the adsorption phenomenon. $\mathrm{R}^{2}$ values were lower than those obtained via pseudo first order model; thus, although intraparticle diffusion may have occurred, it was responsible for driving the overall adsorption process.

Although there was no significant difference in adsorption occurring at varying $\mathrm{pH}$ in consonance with previous work, it was observed that the MAC values obtained in all three dosage forms of activated charcoal for acetaminophen adsorption were higher in $\mathrm{pH} 6.5$ than in $\mathrm{pH} 1.2$, thus lending credence to the fact that adsorption was more pronounced in intestinal $\mathrm{pH}$. Therefore, in cases of poisoning, adsorption from the small intestine would be more efficient than that occurring in the gastric region, as has been shown in similar studies [4]. 
Acetaminophen has a very high ease of abuse in Nigeria, first, because of ease of purchase as an over the counter medication requiring no prescription and more disturbingly, the concomitan use acetaminophen with other drugs. In the Nigerian market, diclofenac and aspirin tablet combinations are marketed as combinations with acetaminophen and because they are available to both pharmacies and local medicine peddlers $[8,9]$, duplication of medications containing acetaminophen may arise. Agaba et al [10] found that common analgesics regularly consume was acetaminophen in $58.1 \%$ of respondents with, $28.9 \%$ taking mixture of analgesic containing acetaminophen and acetaminophen abuse bordering on an overdose was present in $22.6 \%$ of the respondents.

These data make it imperative that activated charcoal formulations available in the market be such that are effective in preventing hepatotoxicity by rapid adsorption of acetaminophen in both the stomach and the small intestine. The dose of acetaminophen widely accepted as hepatotoxic is $145 \mathrm{mg} / \mathrm{kg}$ body weight [13]; thus with MAC values ranging from 139.38 to $301.92 \mathrm{mg} / \mathrm{g}$ for the varying activated charcoal dosage forms, the charcoals should be effective in countering acetaminophen overdose, especially the powdered dosage form which has the highest MAC.

Ease of administration of the powder presents a draw back for it use thus tablet formulations can be used but would require a larger dose. The activated charcoal capsule should be least preferred for the treatment of acetaminophen poison due to due to its relatively low MAC value.

\section{CONCLUSION}

The presence of excipients in the tablets and capsules causes a retardation in adsorption via intraparticle diffusion especially at the basal micropore sites on the activated charcoal surface, especially with adsorption of acetaminophen powder occuring largely via the pseudo first order kinetics. Activated charcoal powder was deemed the best dosage form for countering acetaminophen posioning in emergency situations.

\section{DECLARATIONS}

\section{Acknowledgement}

The authors thank the School of Pharmacy, Faculty of Science, and University of Nottingham
Malaysia Campus for providing facilities for the scanning electron microscope studies

\section{Conflict of Interest}

No conflict of interest associated with this work.

\section{Contribution of Authors}

The authors declare that this work was done by the authors named in this article and all liabilities pertaining to claims relating to the content of this article will be borne by them.

\section{Open Access}

This is an Open Access article that uses a funding model which does not charge readers or their institutions for access and distributed under the terms of the Creative Commons Attribution License (http://creativecommons.org/licenses/by/ 4.0) and the Budapest Open Access Initiative (http://www.budapestopenaccessinitiative.org/rea d), which permit unrestricted use, distribution, and reproduction in any medium, provided the original work is properly credited.

\section{REFERENCES}

1. Dargan PI, Jones AL. Acetaminophen poisoning: An update for the intensivist. Crit Care. 2002; 2(2): 108-110

2. Terzyk AP, Pacholczyk A, Wisniewski M, Gauden PA. Enhanced adsorption of paracetamolon closed nanotubes by formation of nanoaggregates: Carbon nanotubes as potential materials in hot melt drug deposition experiment and simulation. J Coll. Inter Sci. 2012; 376 (1): 209-216

3. Eboka CJ, Afolabi AB. In-Vitro Adsorption of Fluoroquinolones on Some Pharmaceutical Adsorbents. Trop J Pharm Res. 2006; 5(1): 533-538

4. Hoegberg LC, Christophersen AB, Christensen $H R$, Angelo HR. Comparison of the adsorption capacities of an activated-charcoal-yogurt mixture versus activatedcharcoal water slurry in vivo and in vitro. J Clin Toxicol. 2005; 43: 269-275.

5. Hoegberg LC, Angelo HR, Christophersen AB, Christensen HR. Effect of ethanol and $\mathrm{pH}$ on the adsorption of acetaminophen (paracetamol) to high surface activated charcoal, in vitro studies. J Clin Toxicol. 2002; 40(1): 59-67.

6. Ferner RE, Dear JW, Bateman DN. Management of paracetamol poisoning. Brit Med J. 2011; 19(342): d2218

7. FDA. Acetaminophen Prescription Combination Drug Products with more than $325 \mathrm{mg}$ : FDA Statement Recommendation to Discontinue Prescribing and Dispensing. U.S. Food and Drug Administration (2014). Available

from 
http://www.fda.gov/Safety/MedWatch/SafetyInformation/ SafetyAlertsforHumanMedicalProducts/ucm381650.htm ?source=govdelivery\&utm_medium=email\&utm_source =govdelivery.

8. Oshikoya KA, Njokanma OF, Bello JA, Ayorinde EO. The use of prescribed and non-prescribed drugs in infants in Lagos, Nigeria. J Med Sci. 2008;8: 111-7

9. Oshikoya KA, Njokanma OF, Chukwura HA, Ojo OI. Adverse drug reactions in Nigerian children. Paed Perinat Drug Ther. 2007;8 : 81-8

10. Agaba El, Agaba PA, Wigwe CM. Use and abuse of analgesics in Nigeria: a community survey Niger $\mathrm{J}$ Med. 2004; 13(4): 379-82.

11. Spiller HA, Winter ML, Klein-Schwartz W, Bangh SA. Efficacy of activated charcoal administered more than four hours after acetaminophen overdose. J Emerg Med. 2006; 30(1): 1-5

12. James LP, Capparelli EV, Simpson PM, Letzig L, Roberts $D$, Hinson JA. Acetaminophen-associated hepatic injury: evaluation of acetaminophen protein adducts in children and adolescents with acetaminophen overdose. Clin Pharmacol Ther. 2008; 84(6): 684-90.

13. Zyoud SH, Awang R, Sulaiman SA, Al-Jabi SW. Impact of serum acetaminophen concentration on changes in serum potassium, creatinine and urea concentrations among patients with acetaminophen overdose. Pharmacoepidemiol Drug Saf. 2011; 20(2): 203-8

14. Aworn, A, Thiravetyan $P$, Nakbanpote W. Preparation and characteristics of agricultural waste activated carbon by physical activation having micro- and mesopores, J Anal. Appl. Pyrolysis 2008; 82 : 279-285

15. Brasquet $C$, Rousseau $B$, Estrade-Szwarckopf $H$, Le Cloirec $P$. Observation of activated carbon fibres with SEM and AFM correlation with adsorption data in aqueous solution. Carbon 2000; 38(3): 407-422

16. Gómez-Serrano $V$, Cuerda-Correa EM, FernándezGonzález MC, Alexandre-Franco MF, Macías-García A. Preparation of activated carbons from chestnut wood by phosphoric acid chemical activation. Study of microporosity and fractal dimension. Mater. Lett. 2005; 59(7): 846-853

17. Ash B, Satapathy D, Mukherjee Nanda B, Gumatse JL, Mishra BK. Characterization and application of Activated carbon prepared from waste coir pith. J Sci Indus. Res. 2006; (65): 1008-1012

18. Panthee S, Lohani SP. In vitro adsorption studies of paracetamol to activated charcoal capsule, powder and suspension. Open Tox J. 2008; 2: 22-25

19. Dale EW, Khouloud AA, Lloyd EM. Prediction of adsorption from multi component solutions by Activated carbon using single solute parameters. AAPS Pharm. Sci. Tech. 2002; 3(3): 23.

20. llomuanya $M$, Billa $N$, Ifudu $N$, Igwilo $C$. The effect of pore size and morphology of activated charcoal prepared from midribs of Elaeis guineensis on adsorption of poisons using metronidazole and Escherichia coli 0157:H7 as a case study. J Microsc Ultrastruct. 2017; (5): 32-38, http://dx.doi.org/10.1016/j.jmau.2016.05.001 